\title{
¿Cuál es el compromiso de la ciudadanía española con el mecenazgo cultural y patrimonial?
}

Anna Villarroya Planas | Dpto. de Economía, Universitat de Barcelona

URL de la contribución <www.iaph.es/revistaph/index.php/revistaph/article/view/4570>

Uno de los principales elementos a tener en cuenta en el análisis del mecenazgo cultural en cualquier país es el nivel de compromiso que la ciudadanía siente hacia el fomento de las artes y la cultura. Según los datos del Special Eurobarometer 466. Cultural Heritage. Report de la Comisión Europea, en 2017, un 4\% de los españoles afirmó donar recursos monetarios o de otro tipo a organizaciones activas en el campo del patrimonio cultural y un 3\%, realizó trabajo voluntario en tales organizaciones. Estos datos sitúan a España por debajo de la media europea (7\% y $5 \%$ respectivamente) y lejos de países como Holanda o Suecia, en los que el 19\% y $14 \%$ respectivamente de la ciudadanía realiza donaciones al sector patrimonial.

La encuesta permite conocer también la opinión de la ciudadanía sobre los agentes en los que debería recaer la mayor responsabilidad en la protección del patrimonio cultural. En el caso de España, la ciudadanía otorga un papel principal a la Unión Europea (con un 49\% de las respuestas, 9 puntos por encima de la media europea), así como a las autoridades nacionales (44\%, 2 puntos por debajo de la media europea) y a los gobiernos locales y regionales (36\%, 3 puntos por debajo de la media europea). En un lugar intermedio, sitúa a la sociedad civil (31\%) y con una papel mucho más secundario, a las empresas privadas (16\%), los benefactores y sponsors (15\%), así como a las asociaciones y otras entidades del tercer sector (14\%). A excepción de las empresas privadas, la actitud de la población española en torno al papel de la sociedad civil y el tercer sector en la salvaguarda y, por tanto, en la financiación del patrimonio se sitúa por debajo de la media europea.

También desde una perspectiva europea, el estudio de Voldere y Zeqo (2017) sobre el crowdfunding en los sec- tores culturales y creativos en Europa muestra un papel residual del patrimonio (con menos del 1\% de las campañas y del volumen de transacciones), situándolo lejos del $33 \%$ y $29 \%$ respectivamente del sector del cine y audiovisual. España se sitúa, con 3 campañas en el sector patrimonial, en octavo lugar, muy lejos de las 128 del Reino Unido o de las 51 de Francia. En cuanto al modelo utilizado, a diferencia del resto de sectores en los que predomina el modelo de recompensa (presente en el $80 \%$ de las campañas), el sector patrimonial se caracteriza por una menor presencia de este modelo (con un $63 \%$ de las campañas analizadas) y un mayor protagonismo del modelo de donaciones (36\%). El mismo informe apunta a la mayor representatividad de las entidades públicas en el sector patrimonial como una de las razones que explican la diferencia de modelos, así como la menor presencia del crowdfunding en el sector. En cualquier caso, se trata de un ámbito sobre el que haría falta profundizar en futuros estudios.

Los datos anteriores muestran, pues, por un lado, el papel residual de las campañas de crowdfunding y el volumen de transacciones que tienen por objeto intervenciones patrimoniales en España y, por otro, una ciudadanía que concede un papel principal a las autoridades públicas en la salvaguarda y protección del patrimonio.

El análisis desde una perspectiva europea, en la que cohabitan modelos de política cultural diversos, ofrece, sin lugar a dudas, un buen contexto para la reflexión. Los debates que han tenido lugar en España, en los últimos años, en torno a una nueva ley de mecenazgo, en gran parte, propiciados por la crisis económica de 2008, que provocó la reducción drástica de los recursos públicos destinados a la cultura, no siempre han tenido en cuenta factores históricos y estructurales de la política cultural 


\begin{abstract}
a debate Patrocinio, mecenazgo, crowdfunding ¿compromiso social o marketing interesado?
| coordina Ana Isabel Velasco Rebollo
\end{abstract}

española. En este sentido, el modelo de política cultural española, con un elevado protagonismo de las autoridades públicas y escasa implicación de la ciudadanía en la financiación de las artes, podría explicar las diferencias que se observan entre países europeos (RUBIO AROSTEGUI; VILLARROYA, 2019). A este escaso interés de la ciudadanía por la financiación del patrimonio cabe añadir que más de la mitad de la población española desconoce la existencia de las exenciones fiscales en el fomento de las artes y la cultura (INFORME, 2017). En este sentido, el impulso a la contribución privada en la financiación de la cultura en general y del patrimonio, en particular, debería pasar necesariamente por un mejor conocimiento de los incentivos fiscales existentes, pero también del valor social y económico del patrimonio. Iniciativas, como el Año Europeo del Patrimonio Cultural en 2018, destinadas a sensibilizar a la ciudadanía acerca de la importancia y el valor del patrimonio cultural pueden también facilitar la colaboración (monetaria y de otro tipo) con la ciudadanía. A través de la educación, especialmente de los más jóvenes, pero también de la implementación de modelos de gestión y organización participativos es posible conseguir una mayor implicación del público y generar un sentido de propiedad colectiva en la comunidad. En este sentido, la idea de patrimonio cultural como bien común resulta decisiva para avanzar hacia la participación de la ciudadanía en las labores de protección, valorización, financiación y/o gestión del patrimonio cultural (SANI, 2016).

Más allá de estas reflexiones teóricas es importante tener en cuenta que el primer paso ante cualquier iniciativa de reforma de los instrumentos fiscales y regulatorios existentes es poder disponer de datos desagregados para el sector cultural que permitan una aproximación cuantitativa de la contribución que la ciudadanía y las empresas realizan al mecenazgo cultural y patrimonial en España. Sin datos que permitan dimensionar el mecenazgo en el sector, cualquier cambio en el sistema de incentivos tendrá un impacto limitado y seguramente ineficiente. En este sentido, es urgente introducir una cultura de la evaluación de las políticas, programas e iniciativas implementadas por el sector público, que sirvan de evidencia respecto a aquello que funciona o no funciona dentro de la administración (RUBIO AROSTEGUI; VILLARROYA, 2019).

\section{BIBLIOGRAFÍA}

- DE VOldERE, I.; ZEQO, K. (2017) Crowdfunding. Reshaping the crowd's engagement in culture. Luxembourg: Publications Office of the European Union, 2017

- RUBIO AROSTEGUI, J.A.; VILLAROYA PLANAS, A. (2019) El papel del mecenazgo en la política española. Propuestas para reconfigurar su papel en la crisis en las artes y la industria cultural [en línea]. [Madrid]: Ministerio de Cultura y Deporte (trabajo realizado por Fundación Alternativas para Unidad Culturay Mecenazgo), marzo 2019 <http://www.culturaydeporte. gob.es/dam/jcr:fc0e64ed-7450-4878-a854-0e39e52bfc75/ papeldelmecenazgo.pdf> [Consulta: 09/01/2020]

- SANI, M. (2016) La gobernanza participativa del patrimonio cultural. Observatorio Social de "la Caixa" [en línea], Septiembre $2016<$ <ttps://observatoriosociallacaixa.org/es/ -/la-gobernanza-participativa-del-patrimonio-cultural? $\mathrm{ga}=2.263061001 .487664743 .1577798245-619565211.15 \overline{7}$ 2250915> [Consulta: 09/01/2020]

- SPECIAL Eurobarometer 466. Cultural Heritage. Report [en línea]. European Union, September-October $2017<$ https:// data.europa.eu/euodp/data/dataset/S2150_88_1_466_ENG> [Consulta: 09/01/2020]

- INFORME sobre la percepción acerca de las características, fines y motivaciones de las fundaciones en España. sl: Asociación Española de Fundaciones, marzo 2017 (estudio realizado por Sigmados, Análisis e Investigación) Disponible en línea <http://www.fundaciones.org/EPORTAL DOCS/GENERAL/AEF/DOC-cw595205b4c8435/Informe percepciOnfundacionesmarzo2017.pdf> [Consulta: 09/01/2020] 